\title{
Comparative Study on Major and Trace Mineral Content of Edible and Eggshell Powders from Ethiopian Local and Exotic Breed Chicken Eggs
}

\author{
Esayas Abrha*1 Zerihun Asefa ${ }^{2}$ \\ Ethiopian Institute of Agricultural Research (EIAR), \\ Holeta Agricultural Research Center P.O.BOX 2003 Addis Ababa, Ethiopia
}

Highlights

- The aim was to compare the mineral content of edible and egg-shell powder

- Local and exotic breed eggs were used for this study

- Major and trace mineral content of edible and egg-shell were analyzed

- Calcium, Iron, and Zinc mineral content of edible and egg-shell were significantly different

- Mineral contents are detectable and measurable using FAAS

\section{Graphical Abstracts}
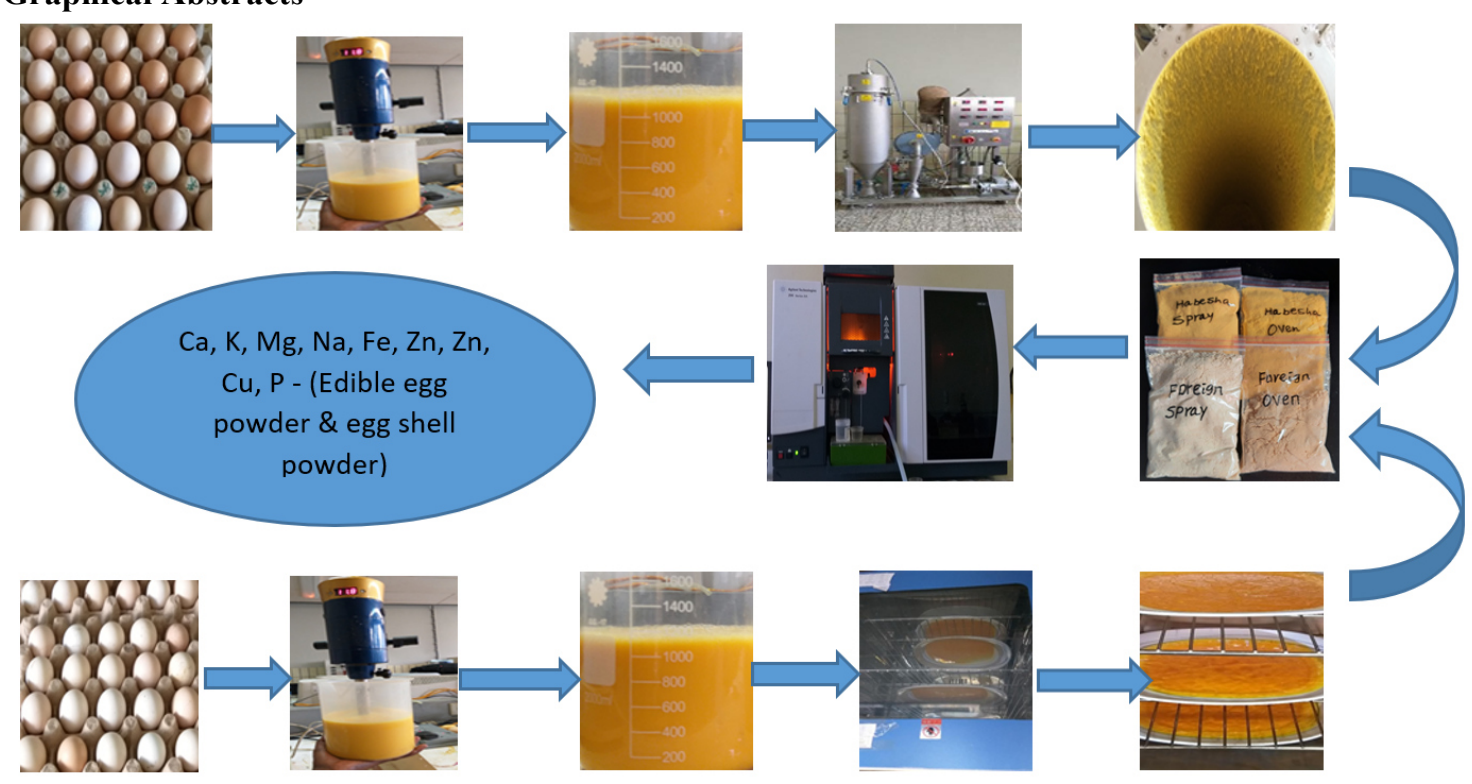

\begin{abstract}
In this study, the effect on the mineral content of eggs from local and exotic breed hens was investigated. For this study, random samples were collected from the Ethiopian Institute of Agricultural Research, Debrezeit Agricultural Research Center, and Fresh Corner Poultry Farming Debrezeite, Ethiopia for the exotic and local breed eggs respectively. Eggshells and edible portion of the egg were analyzed for Calcium (Ca), Potassium (K), Phosphors (P), Sodium (Na), Magnesium (Mg), Iron (Fe), Zinc ( $\mathrm{Zn})$, Manganese ( $\mathrm{Mn})$, and Copper $(\mathrm{Cu})$ contents. The Phosphors and Zinc contents of the edible egg portion were higher in the local breed eggs than in exotic breed eggs. Calcium and Magnesium content of the eggshell was higher in local breed eggs while $\mathrm{Zn}$ content showed a marked decrease. As far as Potassium, Magnesium, Sodium Phosphors, and Copper values were concerned, these did not differ between the eggs from local and exotic breed types. The present finding provides sizeable differences in mineral content between the eggs from the local and exotic breed hens. The results afford a point of departure measurements of major and trace mineral contents of eggs and suggest quantifiable differences amid eggs from hens in different husbandry systems, and hens breed types. The physiological significance of those differences is discussed. But, future studies should elucidate differences observed by crossbreed types, diet effect, and husbandry system. Drying eggs can be a workable food systems intervention that can mend the wellbeing and eminence of diets in low-income countries like Ethiopia.
\end{abstract}

Keywords: Egg, Hen, Mineral Content, Local breed, Exotic breed, Food System, Low-income

DOI: $10.7176 / \mathrm{CPER} / 64-01$

Publication date: January $31^{\text {st }} 2022$ 


\section{Introduction}

Currently, the knowledge on the inorganic composition of local and crossbreed chicken eggs is exceedingly compulsory for different dedications; these take account of the guesstimate of accumulation of venomous species from the intensive and extensive hen rearing systems (Pappas et al., 2006), the protagonist of egg composition for embryonic development (Surai, 2002) and the contribution of egg composition in human nutrition (Pappas et al., 2006). To the extent that the consumption of eggs by human beings is concerned; chicken eggs are increasingly recognized as an imperative source of nutrients including major and trace minerals (Surai and Sparks, 2001). Eggs and components of an egg are widely used as ingredients in the food industry because of their nutritional, functional, and sensory qualities. They are mainly interesting because of their nutritional quality such as high-quality proteins, lipids, vitamins, and minerals (Walker et al., 2012).

In Ethiopia context, eggs are recognized by nonprofessional consumers in the class of; 'i) the smaller eggs with deep-yellow colored yolk known as Habesha (local) egg, and; ii) the larger eggs with lighter yellow yolk known as Ferengi eggs and obtained from imported breeds (exotic) egg' (Abreha et al., 2021). Despite this differentiation and consumer preference for the local breed egg, petite information exists about the difference in the nutritional and techno-functional composition of these two egg types, and how they are impacted by drying techniques and breed type variation. Such information is timely and can inform food systems' interventions that aim to improve the adoption of healthy diets.

The quality of food products has received great attention due to their influence on human nutrition and health. In this context, the determination of trace minerals in foods has become an important field in food analysis (Demirel et al., 2008; Reyes and Campos, 2006; Tuzen and Soylak, 2007). However, the truthful determination of trace elements in hen eggs is still an analytical encounter, due to their stumpy concentration level and the complications that arise from milieu characteristics. Many clients in Europe have faith that eggs instigated from free-range or organic farms taste superior, have an advanced nutritional value, and can be valuable for human health (Rodic et al., 2006). In the face of the substantial interest in the mineral composition of chicken eggs from many standpoints, data on the levels of major and trace elements in eggs of various types of husbandry are inadequate.

Flame atomic absorption spectrometry (FAAS) is a powerful detection technique for determining nutritionally beneficial elements. The advantages of flame atomic absorption spectrometry include well-known interferences, low operator skill required for operation, and comparatively low cost of instrumentation and maintenance (Welz and Sperling, 1999). One drawback, however, is the sample pre-treatment which is a compulsory step for determining trace minerals in multifaceted matrices such as eggs. Due to its high viscosity and content of organic matter, direct egg analysis is particularly difficult.

Therefore, this study aimed to assess the difference among major and trace mineral composition of whole egg and eggshell from Ethiopian local and exotic breed hens by making the edible and egg-shell to a powder form using a suitable drying technology. A baseline dataset of the major and trace mineral content of edible and eggshell has also been established.

\section{Materials and Methods}

\subsection{Raw materials: egg sample collection and preparation}

Chicken eggs (Gallus Gallus) from exotic breeds $(n=150)$ and local breeds $(n=150)$ were obtained from the poultry research program at Debrezeit Agricultural Research Center, Ethiopian Institute of Agricultural Research, and from fresh corner private poultry farm, at Debrezait, Ethiopia respectively. The eggs were all three days old and their freshness was further checked using candling techniques (Sebastián et al., 2018). This simple test has faith in the principle that as eggs age, the shell comes to be more porous consenting air to flow through making the air cell larger. After screening for freshness, the eggs were washed, broken, and de-shelled manually following aseptic procedures. The liquid whole egg (yolk and egg white) was homogenized, pasteurized in a water-bath at $70^{\circ} \mathrm{C}$ for $3 \mathrm{~min}$. Finally, the whole egg liquid and egg-shell were oven-dried using ventilated oven drier.

\subsection{Reagents and Chemicals}

Analytical reagents-grade chemicals were used in the preparation of all solutions. Entirely the plastic and glassware were gutted by soaking in dilute nitric acid $(1+9)$ and were sluiced with distilled water before use. Nitric acid $(65 \%)$, and (30\%) hydrogen peroxide were supplied by Merck (Germany). Sodium (Na), potassium (K), calcium $(\mathrm{Ca})$, magnesium $(\mathrm{Mg})$, zinc $(\mathrm{Zn})$, iron $(\mathrm{Fe})$, manganese $(\mathrm{Mn})$, and copper $(\mathrm{Cu})$ standard solutions $(1000 \mathrm{mg} \mathrm{L}-1)$ were obtained from the Ethiopian Institute of Agricultural Research (EIAR, Ethiopia) and diluted as necessary to obtain working standards.

\subsection{Instrumentation/ Procedure}

All measurements were carried out using an Agilent 240 AA series (Agilent, USA) model Agilent 240 atomic absorption spectrometer equipped with Spectra AA (Agilent, Australia) hollow cathode lamps as the radiation 
source. Acetylene-air and acetylene-nitrous oxide flame was used; the gas flow rates and the burner height were adjusted to obtain the maximum absorbance signal for each element. Other instrumental parameters were set to the values shown in (Table 1).

Table 1: Instrumental conditions and operating parameters setting

\begin{tabular}{llll}
\hline Nebulizer & Bergner PEEK MiraMist & Auto integration & $5-10 \mathrm{sec}$ (Min-Max) \\
Spray chamber & cyclonic & Data processing model & Peak area \\
RF power & $1200 \mathrm{~W}$ & Read delay & $10 \mathrm{sec}$ \\
Flame type & Air-Acetylene & Rinse delay & $10 \mathrm{sec}$ \\
Nebulizer acetylene flow & $2 \mathrm{ml} / \mathrm{min}$ & replicates & 3 \\
Nebulizer airflow & $10 \mathrm{ml} / \mathrm{min}$ & Oxidant & Air/ Nitrous Oxide \\
Sample uptake rate & Tube valve & Energy source & Hallo-Cathode lamp \\
\hline
\end{tabular}

\subsection{Drying}

Oven drying: Oven drying of the edible egg and eggshell was carried out according to (Abreha et al., 2021) in a ventilated oven at $44{ }^{\circ} \mathrm{C}$ in place of $6 \mathrm{~h}$. (DHG- 9123A Michel, England). The dried whole egg and eggshell were permitted to cool; the flakes were bundled, pulverized using a coffee grinder (FW 100, China), and put through a sieve to card over and done with a $60 \mathrm{~mm}$ mesh. The resultant edible egg powder and eggshell powder were bagged in self-seal polyethylene bags and were stored at $-8^{\circ} \mathrm{C}$ in anticipation of further analyses.

\subsection{Mineral Analysis}

The concentration of the major minerals (calcium, potassium, sodium, magnesium, and phosphorus) and trace minerals (iron, zinc, copper, and manganese) was determined using the official method of AOAC,(Horwitz, 2010) code 923.03 in edible egg and eggshell portions. Briefly, $1 \mathrm{~g}$ of edible and eggshell powder was ashed using a muffle furnace (Carbolite, Aston Lane, Hope, Sheffield s30 2RR, England) at $550^{\circ} \mathrm{C}$ for $4 \mathrm{~h}$. The ash was liquefied in $5 \mathrm{~mL}$ of $6 \mathrm{M} \mathrm{HCl}$. Subsequently, $15 \mathrm{~mL}$ of $3 \mathrm{M} \mathrm{HCl}$ was added and heated till the solution boiled. The assimilated sample was cooled, filtered, and adjusted to the required volume using distilled water. The mineral concentration was determined using a flame atomic absorption spectrophotometer (AAS 4200, Agilent, USA).

Mineral Content $(m g / k g)=\left(\frac{(\mathrm{R}-\mathrm{b}) * \mathrm{TV} * \mathrm{df}}{\mathrm{Swt}}\right)$

Whereas, R-Sample Reading B-blank reading Tv-total volume of aliquot extracted (50mL) Df-dilution factor when sample concentration above the calibration carve the sample concentration diluted by distilled water, Swt-sample weight used for analysis

Phosphorus was determined using a UV-Vis spectrophotometer (JANEWAY 6300, UK) at $690 \mathrm{~nm}$, according to the AOAC method (AOAC 965.17) (Latimer, 2016).

Phosphors $(\mathrm{mg} / \mathrm{kg})=\left(\frac{(\mathrm{R}-\mathrm{b}) * \mathrm{TV} * \mathrm{df}}{\mathrm{S} * \text { Aliq }}\right)$

Whereas, R-Sample Reading B-blank reading Tv-total volume of aliquot extracted (50mL) Df-dilution factor when sample concentration above the calibration carve the sample concentration diluted by distilled water, Swtsample weight used for analysis, and Aliq-sample aliquot used for reading

\subsection{Statistical Analysis}

Results were expressed as major and trace minerals mean values \pm standard deviation, separately for edible egg portion and eggshell. Comparisons between the two egg types and egg components (whole egg and eggshell) were made using an independent t-test. $P$-values $<0.05$ were considered statistically significant. All analyses were accompanied in triplicate and were analyzed through SPSS software version 22.0 (SPSS Inc. Illinois, USA).

\section{Results and Discussion}

The examination of major and trace minerals in eggshell powder and whole egg powder samples was determined by the FAAS method. All major and trace minerals measurements were carried out using the Agilent Flame Atomic Absorption Spectroscopy Method (Model: Agilent 4200, USA, Serial number: MY15400002, and product number: G8431A) and the Flame Atomic Absorption Spector-photometer operating conditions are listed in (Table-2).

The macro-mineral composition of the whole egg powder such as calcium, magnesium, potassium, sodium, and phosphorus was analyzed and results were given in (Table 3). Some of the minerals are not disaggregated by egg type as this does not affect mineral content. Certainly, no significant differences between egg powders for oven-dried, local and exotic breed eggs were observed for magnesium, potassium, sodium, and phosphorus. While for the oven-dried whole egg only calcium was significantly higher in the egg powder for local than exotic breed at $\mathrm{P}<0.05$. Irrespective of the egg type difference edible egg portions were comprising higher potassium and sodium mineral content. 
Table 2: Calibration summary of the operating conditions

\begin{tabular}{lllllll}
\hline Element & Wave length $(\mathrm{nm})$ & standards & Equation & Intercept & Slope & Corr. Coef. \\
\hline Calcium $(\mathrm{Ca})$ & 422.7 & 5 & Linear & 0.6248 & 46.3860 & 0.9989 \\
Potassium $(\mathrm{K})$ & 766.5 & 5 & Linear & 0.2565 & 9.6473 & 0.9944 \\
Magnesium $(\mathrm{Mg})$ & 285.2 & 5 & Linear & 1.0710 & 5.0619 & 0.9701 \\
Sodium $(\mathrm{Na})$ & 589.0 & 5 & Linear & 0.3272 & 3.7121 & 0.9948 \\
Phosphors $(\mathrm{P})$ & 660.0 & 5 & Linear & 0.8946 & 11.9842 & 0.9909 \\
Iron (Fe) & 248.3 & 5 & Linear & 1.3882 & 30.5330 & 0.9887 \\
Zinc (Zn) & 213.9 & 5 & Linear & 0.2934 & 1.8539 & 0.9756 \\
Manganese $(\mathrm{Mn})$ & 279.5 & 5 & Linear & 0.8940 & 12.1510 & 0.9915 \\
Copper $(\mathrm{Cu})$ & 324.8 & 5 & Linear & 0.2548 & 11.9220 & 0.9997 \\
\hline
\end{tabular}

The micro-mineral composition of the whole egg powder such as Iron, Zinc, Manganese, and copper was analyzed and results were presented (Table 3). There are no significant differences between egg powders from local and exotic breeds were observed for copper. Meanwhile iron, zinc, and manganese were however significantly different in the egg powder from the local breed than the exotic breed $(\mathrm{P}<0.05)$. The iron, zinc, and manganese content was significantly higher in the egg powder from the local than exotic breed egg-types, whereas copper was not significantly different for the local and exotic egg-types statistically at $\mathrm{P}<0.05$.

The elements such as calcium, potassium, sodium, magnesium, phosphorous, iron, manganese, zinc, and copper of the eggshell powders were analyzed and results were given in (Table-4). Among the major mineral contents, calcium and potassium were showing a significant difference on eggshell powders statistically at $\mathrm{p}<0.05$. While, for magnesium, sodium, and phosphors no significant difference was observed for the local and exotic breed eggshell powders. Calcium has shown higher on eggshell powder than the respective major minerals, and this proves eggshell has been taken as a good source of calcium.

The eggshell powder has comparatively lower trace minerals in comparison with major minerals. Local breed eggshell powders have significantly higher in iron, zinc, and manganese than exotic breed eggshell powders statistically at $\mathrm{p}<0.05$. Whereas, no significant variation was observed in copper content for local and exotic breed eggshell powders. Among the trace mineral content on eggshell, powder iron was showing higher value in contrast with those zinc, manganese, and copper. In eggshell powders, calcium and magnesium were highest.

Table 3: Macro- and trace- mineral composition of edible egg powder from Ethiopian local and exotic egg types

\begin{tabular}{|c|c|c|c|c|c|}
\hline \multirow[b]{3}{*}{ Element } & \multicolumn{5}{|c|}{ Mineral content estimation in dehydrated egg powder by FAAS } \\
\hline & \multirow[b]{2}{*}{$\begin{array}{c}\text { Wavelength } \\
(\mathrm{nm})\end{array}$} & \multicolumn{3}{|c|}{ Results mg/kg of edible egg powder (dry basis) } & \multirow[b]{2}{*}{$\begin{array}{l}\text { Detection limit } \\
(\mathrm{ppm})\end{array}$} \\
\hline & & Local egg & Exotic egg & P-value & \\
\hline Calcium $(\mathrm{Ca})$ & 422.7 & $197.0 \pm 0.15$ & $120.0 \pm 0.10$ & 0.002 & $0.001 \mathrm{mg} / \mathrm{L}$ \\
\hline Potassium (K) & 766.5 & $696.0 \pm 0.23$ & $686.0 \pm 0.04$ & 0.516 & $0.003 \mathrm{mg} / \mathrm{L}$ \\
\hline Magnesium (Mg) & 285.2 & $121.0 \pm 0.17$ & $115.0 \pm 0.01$ & 0.053 & $0.0003 \mathrm{mg} / \mathrm{L}$ \\
\hline Sodium $(\mathrm{Na})$ & 589.0 & $521.0 \pm 0.34$ & $494.0 \pm 0.02$ & 0.263 & $0.0002 \mathrm{mg} / \mathrm{L}$ \\
\hline Phosphors (P) & 660.0 & $185.0 \pm 0.07$ & $177.0 \pm 0.1$ & 0.325 & $0.004 \mathrm{mg} / \mathrm{L}$ \\
\hline Iron $(\mathrm{Fe})$ & 248.3 & $17.3 \pm 0.37$ & $11.8 \pm 0.14$ & 0.049 & $0.006 \mathrm{mg} / \mathrm{L}$ \\
\hline Zinc (Zn) & 213.9 & $1.36 \pm 0.25$ & $1.09 \pm 0.17$ & 0.043 & $0.001 \mathrm{mg} / \mathrm{L}$ \\
\hline Manganese (Mn) & 279.5 & $0.25 \pm 0.26$ & $0.19 \pm 0.23$ & 0.039 & $0.002 \mathrm{mg} / \mathrm{L}$ \\
\hline Copper $(\mathrm{Cu})$ & 324.8 & $0.37 \pm 0.01$ & $0.39 \pm 0.02$ & 0.071 & $0.003 \mathrm{mg} / \mathrm{L}$ \\
\hline
\end{tabular}

Table 4: Macro- and trace- mineral composition of eggshell powder from Ethiopian local and exotic egg types

\begin{tabular}{llllll}
\hline & \multicolumn{5}{c}{ Mineral content estimation in eggshell powder by FAAS } \\
\cline { 1 - 3 } \multicolumn{1}{c}{ Element } & Wavelength $(\mathrm{nm})$ & \multicolumn{2}{c}{ Results $\mathrm{mg} / \mathrm{kg}$ of eggshell powder (dry basis) } & \\
\cline { 4 - 5 } Calcium $(\mathrm{Ca})$ & 422.7 & $8256.0 \pm 5.12$ & $5819.0 \pm 1.53$ & 0.001 & $0.001 \mathrm{mg} / \mathrm{L}$ \\
Potassium $(\mathrm{K})$ & 766.5 & $236.0 \pm 0.14$ & $181.0 \pm 0.20$ & 0.018 & $0.003 \mathrm{mg} / \mathrm{L}$ \\
Magnesium $(\mathrm{Mg})$ & 285.2 & $672.0 \pm 0.34$ & $550.0 \pm 0.77$ & 0.066 & $0.0003 \mathrm{mg} / \mathrm{L}$ \\
Sodium $(\mathrm{Na})$ & 589.0 & $127.0 \pm 0.08$ & $108.0 \pm 0.11$ & 0.075 & $0.0002 \mathrm{mg} / \mathrm{L}$ \\
Phosphors $(\mathrm{P})$ & 660.0 & $65.0 \pm 0.02$ & $69.0 \pm 0.06$ & 0.358 & $0.004 \mathrm{mg} / \mathrm{L}$ \\
Iron (Fe) & 248.3 & $6.46 \pm 0.40$ & $5.41 \pm 0.25$ & 0.015 & $0.006 \mathrm{mg} / \mathrm{L}$ \\
Zinc $(\mathrm{Zn})$ & 213.9 & $0.33 \pm 0.01$ & $0.17 \pm 0.01$ & 0.003 & $0.001 \mathrm{mg} / \mathrm{L}$ \\
Manganese $(\mathrm{Mn})$ & 279.5 & $0.58 \pm 0.01$ & $0.36 \pm 0.01$ & 0.019 & $0.002 \mathrm{mg} / \mathrm{L}$ \\
Copper $(\mathrm{Cu})$ & 324.8 & $0.34 \pm 0.05$ & $0.35 \pm 0.04$ & 0.617 & $0.003 \mathrm{mg} / \mathrm{L}$ \\
\hline
\end{tabular}

Determination of trace minerals in eggs can become an important tool for nutritionists and environmentalists. Our current study was designed to deliver a baseline of the composition of domestic avian and exotic breed eggs 
in major and trace minerals; such information had been previously lacking extensively. There has been some information on individual major and trace mineral content, especially for chicken eggs due to their relative importance. To the extent that the feasting of eggs by humans is concerned, chicken eggs are recognized increasingly as an imperative source of nutrients, including micro minerals (Surai and Sparks, 2001). Currently, there is extensive interest in the trace mineral composition of eggs of hens from the viewpoints of human health (Kiliç et al., 2002).

Table 5: Macro- and trace- mineral composition of eggshell powder from Ethiopian local and exotic egg types

\begin{tabular}{|c|c|c|c|c|c|}
\hline \multirow{3}{*}{ Element } & \multirow{3}{*}{ Egg type } & \multicolumn{4}{|c|}{ Mineral content estimation in dehydrated egg powder and eggshell by FAAS } \\
\hline & & \multirow{2}{*}{$\begin{array}{l}\text { Wavelength } \\
\quad(\mathrm{nm})\end{array}$} & \multicolumn{2}{|c|}{$\begin{array}{c}\text { Results } \mathrm{mg} / \mathrm{kg} \text { of whole egg powder (dry } \\
\text { basis) }\end{array}$} & \multirow{2}{*}{$\begin{array}{l}\text { Detection } \\
\text { limit (ppm) }\end{array}$} \\
\hline & & & Whole egg powder & Eggshell powder & \\
\hline \multirow[t]{2}{*}{ Calcium $(\mathrm{Ca})$} & Local & 422.7 & $197.0 \pm 0.15^{\mathrm{aA}}$ & $8256.0 \pm 5.12^{\mathrm{aA}}$ & $0.001 \mathrm{mg} / \mathrm{L}$ \\
\hline & Exotic & & $120.0 \pm 0.10^{\mathrm{bB}}$ & $5819.0 \pm 1.53^{\mathrm{aB}}$ & \\
\hline \multirow[t]{2}{*}{ Potassium $(\mathrm{K})$} & Local & 766.5 & $696.0 \pm 0.23^{\mathrm{aA}}$ & $236.0 \pm 0.14^{\mathrm{bA}}$ & $0.003 \mathrm{mg} / \mathrm{L}$ \\
\hline & Exotic & & $686.0 \pm 0.04^{\mathrm{aA}}$ & $181.0 \pm 0.20^{\mathrm{bB}}$ & \\
\hline \multirow{2}{*}{$\begin{array}{l}\text { Magnesium } \\
(\mathrm{Mg})\end{array}$} & Local & 285.2 & $121.0 \pm 0.17^{\mathrm{bB}}$ & $672.0 \pm 0.34^{\mathrm{aA}}$ & $0.0003 \mathrm{mg} / \mathrm{L}$ \\
\hline & Exotic & & $115.0 \pm 0.01^{\mathrm{bB}}$ & $550.0 \pm 0.77^{\mathrm{aA}}$ & \\
\hline \multirow[t]{2}{*}{ Sodium $(\mathrm{Na})$} & Local & 589.0 & $521.0 \pm 0.34^{\mathrm{aA}}$ & $127.0 \pm 0.08^{\mathrm{bB}}$ & $0.0002 \mathrm{mg} / \mathrm{L}$ \\
\hline & Exotic & & $494.0 \pm 0.02^{\mathrm{aA}}$ & $108.0 \pm 0.11^{\mathrm{bB}}$ & \\
\hline \multirow[t]{2}{*}{ Phosphors (P) } & Local & 660.0 & $185.0 \pm 0.07^{\mathrm{aA}}$ & $65.0 \pm 0.02^{\mathrm{bB}}$ & $0.004 \mathrm{mg} / \mathrm{L}$ \\
\hline & Exotic & & $177.0 \pm 0.1^{\mathrm{aA}}$ & $69.0 \pm 0.06^{\mathrm{bB}}$ & \\
\hline \multirow[t]{2}{*}{ Iron $(\mathrm{Fe})$} & Local & 248.3 & $17.3 \pm 0.37^{\mathrm{aA}}$ & $6.46 \pm 0.40^{\mathrm{bA}}$ & $0.006 \mathrm{mg} / \mathrm{L}$ \\
\hline & Exotic & & $11.8 \pm 0.14^{\mathrm{aB}}$ & $5.41 \pm 0.25^{\mathrm{bB}}$ & \\
\hline \multirow[t]{2}{*}{ Zinc (Zn) } & Local & 213.9 & $1.36 \pm 0.25^{\mathrm{aA}}$ & $0.33 \pm 0.01^{\mathrm{bA}}$ & $0.001 \mathrm{mg} / \mathrm{L}$ \\
\hline & Exotic & & $1.09 \pm 0.17^{\mathrm{aB}}$ & $0.17 \pm 0.01^{\mathrm{bB}}$ & \\
\hline \multirow{2}{*}{ Manganese (Mn) } & Local & 279.5 & $0.25 \pm 0.26^{\mathrm{bA}}$ & $0.58 \pm 0.01^{\mathrm{aA}}$ & $0.002 \mathrm{mg} / \mathrm{L}$ \\
\hline & Exotic & & $0.19 \pm 0.23^{\mathrm{bB}}$ & $0.36 \pm 0.01^{\mathrm{aB}}$ & \\
\hline \multirow[t]{2}{*}{ Copper $(\mathrm{Cu})$} & Local & 324.8 & $0.37 \pm 0.11^{\mathrm{bA}}$ & $0.34 \pm 0.05^{\mathrm{bB}}$ & $0.003 \mathrm{mg} / \mathrm{L}$ \\
\hline & Exotic & & $0.39 \pm 0.02^{\mathrm{aA}}$ & $0.35 \pm 0.04^{\mathrm{aB}}$ & \\
\hline
\end{tabular}

Values are given as mean $+S E(n=3)$. The different lowercase letters in the same raw and different capital letters in the same column within the same parameter denote a significant difference $(P<0.05)$ using the student's independent t-test.

Our findings for major and trace element levels for the different local and exotic breed eggs could be compared to individual major and trace mineral levels reports in the literature. The eggshell has remarkably taken as high a content of calcium and magnesium as the edible egg portion. In the meantime potassium, iron, zinc, and phosphorus were higher in the edible egg portion.

The edible egg portion has taken as a competent source of iron, zinc, potassium, and calcium in addition to its good potential for its protein and fat sources. Indefinite fact, it is painstaking that the content of standard grainbased diets may not be enough to accomplish the 'ideal' concentration of trace elements in the egg (Surai, 2002), but, interestingly some authors (Sparks, 2006; Surai and Sparks, 2001) have suggested that concentration of certain trace elements of eggs can be modified through the diet. Such augmented or invigorated eggs could be used to progress in cooperation with human nutrition and chick embryo viability.

The significant difference in mineral content of local and exotic breed eggs might be due to the difference in the rearing system of hens, and feed types. Our assumption was in agreement with arguments by (Küçükyılmaz et al., 2012; Matt et al., 2009) egg mineral contents showed variable responses to the hen rearing systems. Several investigations have shown that macro elements including calcium, phosphorus, and magnesium are provided by both feed ingredients and supplemental mineral rocks, such as limestone and dicalcium phosphate. (Küçükyılmaz et al., 2012; Lichtenstein, 1948) mentioned that, from the edible egg portion egg yolk has a large store of calcium that was generously being used for human nutrition.

Chicken eggs are ever more recognized as an important cradle of nutrients, including micro minerals. The food and drug administration regulations require nutrition labeling for most foods. Daily intake reference for some essential elements of human nutrition and daily reference values have been established, namely: Calcium (1000 $\mathrm{mg}$ ), Copper (2 mg), Iron (18 mg), Potassium (3500 mg), Magnesium (400 mg), Manganese (2 mg), Phosphors $(1000 \mathrm{mg})$ and Zinc $(15 \mathrm{mg})$ (Dolan and Capar, 2002). Hence the measurements of major and trace minerals are as well very helpful in the assessment of the quality of egg powder during production in manufacturing industries.

To some extent, the nonexistence of information on the composition of chicken eggs in other micro minerals in the literature, despite the increased interest in it, reflects mainly the teething troubles in determination methods. With its limitations, atomic absorption spectroscopy was widely used in the determination of the micro minerals in various food types. The study of (Kirkpatrick and Coffin, 1975) have measured that, the concentration of trace 
minerals through the use of atomic absorption spectroscopy.

\section{Conclusions}

To our knowledge, this is the first study analyzing the major and trace mineral content of local (Habesha) eggs and comparing it to exotic eggs for which data is ample. As such the present study has several strengths and limitations, our study shows that the content of numerous major and trace elements in eggs of the local and exotic breed species can be readily measured through the Flame Atomic Absorption Spectroscopy methodology and that these vary considerably among the breed species. The measurements can afford us baseline information on the composition of several eggs and the range of major and trace element levels that naturally occur in different breeds. The study could not, however, analyze all relevant major and trace mineral contents because of technical and financial constraints. Additional investigations hooked on how different dietary intakes of trace elements upset egg composition is now warranted and the same practice can be castoff for this perseverance. Such inquiries would also offer extra information on the trace element requirements for fowls of different species.

\section{Acknowledgments}

The project management support of the Ethiopian Institute of Agricultural Research is duly acknowledged. EA conceived the study, conducted and oversaw the experiment, and guided the analysis. EA and ZA wrote the first draft and critically reviewed the draft. Both the authors have read and approved the final draft. The authors declare no conflict of interest.

\section{List of Symbols}

AOAC

Corr. Coef.

FAAS

nm

ppm

$\mathrm{UV}-\mathrm{V}$ is

Association of Official Analytical Chemists

Correction Coefficient

Flame Atomic Absorption Spectroscopy

Nano Meter

Parts Per Million

UV-Visible Spectroscopy

\section{ORCID}

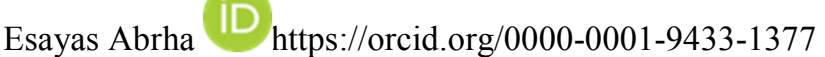

\section{Reference}

Abreha, E., Getachew, P., Laillou, A., Chitekwe, S., \& Baye, K. (2021). Physico-chemical and functionality of air and spray dried egg powder: implications to improving diets. International Journal of Food Properties, 24(1), $152-162$

Demirel, S., Tuzen, M., Saracoglu, S., \& Soylak, M. (2008). Evaluation of various digestion procedures for trace element contents of some food materials. Journal of hazardous materials, 152(3), 1020-1026.

Dolan, S. P., \& Capar, S. G. (2002). Multi-element analysis of food by microwave digestion and inductively coupled plasma-atomic emission spectrometry. Journal of Food Composition and Analysis, 15(5), 593-615.

Horwitz, W. (2010). Official methods of analysis of AOAC International. Volume I, agricultural chemicals, contaminants, drugs/edited by William Horwitz: Gaithersburg (Maryland): AOAC International, 1997.

Kiliç, Z., Acar, O., Ulaşan, M., \& Ilim, M. (2002). Determination of lead, copper, zinc, magnesium, calcium, and iron in fresh eggs by atomic absorption spectrometry. Food Chemistry, 76(1), 107-116.

Kirkpatrick, D. C., \& Coffin, D. E. (1975). Trace metal content of chicken eggs. Journal of the Science of Food and Agriculture, 26(1), 99-103.

Küçükyılmaz, K., Bozkurt, M., Yamaner, Ç., Çınar, M., Çatlı, A., \& Konak, R. (2012). Effect of an organic and conventional rearing system on the mineral content of hen eggs. Food Chemistry, 132(2), 989-992.

Latimer, G. (2016). AOAC official method 965.17. Phosphorus in animal feed and pet food. Official Methods of Analysis of AOAC International, -.

Lichtenstein, F. (1948). Eierschalen zur peroralen Kalktherapie. Zentralblatt Fur Gynakologie, 70(4), 346-348.

Matt, D., Veromann, E., \& Luik, A. (2009). Effect of housing systems on biochemical composition of chicken eggs. Agronomy Research, 7(2), 662-667.

Pappas, A. C., Karadas, F., Surai, P. F., Wood, N. A., Cassey, P., Bortolotti, G. R., \& Speake, B. K. (2006). Interspecies variation in yolk selenium concentrations among eggs of free-living birds: The effect of the phylogeny. Journal of Trace Elements in Medicine and Biology, 20(3), 155-160.

Reyes, M. N. M., \& Campos, R. C. (2006). Determination of copper and nickel in vegetable oils by direct sampling graphite furnace atomic absorption spectrometry. Talanta, 70(5), 929-932.

Rodić, V., Perić, L., Vukelić, N., \& Milošević, N. (2006). Consumer's Attitudes Towards Chicken Meat Produced 
in Extensive Systems. Paper presented at the XII European Poultry Conference, Book of Abstracts, World's Poultry Science Journal.

Sebastián, V. C. R., Cecilia, R. S. L., \& Cristina, N. L. M. (2018). Merging Manual and Automated Egg Candling: A Safety and Social Solution. Enfoque UTE, 9(2), 70-76.

Sparks, N. (2006). The hen's egg-is its role in human nutrition changing? World's Poultry Science Journal, 62(2), 308-315.

Surai, P., \& Sparks, N. (2001). Designer eggs: from the improvement of egg composition to functional food. Trends in Food Science \& Technology, 12(1), 7-16.

Surai, P. F. (2002). Natural antioxidants in avian nutrition and reproduction: Nottingham University Press Nottingham.

Tuzen, M., \& Soylak, M. (2007). Evaluation of trace element contents in canned foods marketed from Turkey. Food Chemistry, 102(4), 1089-1095.

Walker, L. A., Wang, T., Xin, H., \& Dolde, D. (2012). Supplementation of laying-hen feed with palm tocos and algae astaxanthin for egg yolk nutrient enrichment. Journal of agricultural and food chemistry, 60(8), 19891999.

Welz, B., \& Sperling, M. (1999). Atomic Absorption Spectrometry. 3rd Willey-VHC. In: Weinheim, Germany. 